\title{
STRUKTUR KOMUNITAS DAN BIOMASSA RUMPUT LAUT (SEAGRASS) DI PERAIRAN DESA TUMBAK KECAMATAN PUSOMAEN ${ }^{1}$
}

\author{
Idris Baba ${ }^{2}$, Ferdinand F Tilaar ${ }^{3}$, Victor NR Watung ${ }^{3}$
}

\begin{abstract}
Seagrass community structure is the basic data of seagrass ecosystems needs to know. Research community structure and biomass of seagrass was conducted in the waters of the Tumbak village, district of Pusomaen Southeast Minahasa North Sulawesi, in June 2012. This study aims to determine the community structure and biomass of seagrass through a review of the species density, species diversity, and evenness of species in the waters. Found seven species of seagrass that is Cymodoceae rotundata, Cymodocea serrulata, Halophila ovalis, Halophila minor, Enhalus acoroides, Thalasia hemprichii and Syringodium isoetifolium.

Keywords : seagrass, community structure, biomass

\section{ABSTRAK}

Struktur komunitas rumput laut merupakan data dasar dari ekosistem rumput laut yang perlu di ketahui. Penelitian struktur komunitas dan biomassa rumput laut (seagrass) ini dilakukan di perairan Desa Tumbak Kecamatan Pusomaen Kabupaten Minahasa Tenggara Sulawesi Utara, pada bulan juni 2012. Penelitian ini bertujuan untuk mengetahui struktur komunitas dan biomassa rumput laut (seagrass) melalui penelahaan kepadatan spesies, keanekaragaman spesies, dan kemerataan spesies Ditemukan tujuh spesies rumput laut yaitu Cymodoceae rotundata, Cymodocea serrulata, Halophila ovalis, Halophila minor, Enhalus acoroides, Thalasia hemprichii dan Syringodium isoetifolium.
\end{abstract}

\section{Kata kunci : rumput laut, struktur komunitas, biomassa \\ ${ }^{1}$ Bagian dari skripsi \\ ${ }^{2}$ Mahasiswa Program Studi Manajemen Sumberdaya Perairan FPIK-UNSRAT \\ ${ }^{3}$ Staf pengajar Fakultas Perikanan dan IImu Kelautan Universitas Sam Ratulangi}

\section{PENDAHULUAN}

Rumput laut adalah tumbuhan berbiji tunggal (monokotil) dari kelas Angiospermae. Tumbuhan ini dapat menyesuaikan diri untuk hidup terbenam di dalam laut (Kordi, 2011). Tumbuhan ini memiliki rhizoma, akar, daun, bunga, dan jaringan-jaringan yang dilapisi lignin sebagai penyalur bahan makanan, air dan gas. Rhizoma merupakan batang yang terbenam dan merayap secara mendatar dan berbuku-buku. Pada buku-buku tersebut tumbuh batang pendek yang tegak ke atas, berdaun dan berbunga. Adapun yang membedakan dengan tumbuhan di darat adalah pada rumput laut tidak ditemukan adanya stomata (Susetiono, 2004).

Ekosistem rumput laut telah dikenal secara luas sebagai ekosistem di perairan dangkal yang mempunyai 
produktivitas sangat tinggi selain ekosistem hutan bakau (mangrove) dan terumbu karang (coral reef). Oleh karena itu keberadaan rumput laut pada suatu perairan akan mendukung produktivitas perairan itu di dalam menyediakan keragaman, kelimpahan, biomassa dan produksi ikan serta stok biota-biota laut ekonomis lainya seperti teripang dan udang. Keberadaan ekosistem rumput laut berperan penting dalam proses-proses yang berlangsung di perairan pantai sebagai: (1) Tempat mencari makan dan persinggahan bagi berbagai tumbuhan serta hewan, (2) Memperkaya produksi primer di perairan pantai, (3) Sebagai stabilisator sedimen dan garis pantai, (4) Sebagai tempat memijah, asuhan dan habitat bagi berbagai jenis ikan dan invertebrata Zieman (1982) dan Nienhuis (1993) in Susetiono, (2004).

Selain itu, ekosistem rumput laut yang berada pada terumbu karang dan di sekitar area perairan estuari berperan sebagai tempat terkumpulnya nutrien, penyaring nutrien dan pemasukan unsur-unsur zat hara bagi lingkungan perairan di sekitarnya (Short, 1987 in Susetiono, 2004). Menurut Kiswara (1996) jenis rumput laut yang di temukan di perairan Indonesia jumlahnya mencapai 13 jenis. Di seluruh dunia jumlah spesies rumput laut 58 spesies yang terdiri dari 12 genera, 4 famili dan 2 ordo (Kuo dan McComb, 1989 in Kordi, 2011)

\section{CMEtode}

Lokasi penelitian ini dilakukan di Desa Tumbak, Kecamatan Pusomaen, Kabupaten Minahasa Tenggara yang terletak pada posisi $124^{\circ} 53^{\prime} 00^{\prime}$ $125^{\circ} 55^{\prime} 00^{\prime}$ BT dan $0^{0} 58^{\prime} 15^{\prime \prime}-0^{\circ} 58^{\prime} 40^{\prime \prime}$ LU. Topografi pantainya penuh dengan terumbu karang yang sudah mulai terdegradasi.

Pengambilan data dilakukan pada saat surut terendah mengikuti garis transek kuadrat, sebelumnya telah dilakukan survey jelajah untuk menentukan lokasi. Pada masing- masing area pengambilan sampel diletakkan 3 garis transek dengan panjang jarak $50 \mathrm{~m}$ ke arah laut, tegak lurus dengan garis pantai dengan jarak antar transek $100 \mathrm{~m}$. Kuadrat yang digunakan berukuran $50 \times 50 \mathrm{~cm}$ dan jumlah kuadrat di setiap transek sebanyak 10. Pengukuran suhu dilakukan di dengan menggunakan termometer batang berketelitian $1{ }^{\circ} \mathrm{C}$ pada area garis transek. Dengan menggunakan refraktosalinometer dilakukampengukuran salinitas, dimana sampel air laut di ambil dan diteteskan pada refraktometer kemudian di amati angka salinitasnya. Spesies rumput laut yang ditemukan dalam kuadrat dihitung jumlah individu tiap spesies per $\mathrm{m}^{2}$. Individu spesies yang tidak terindentifikasi dikoleksi dalam plastik yang sudah diberi label, kemudian disimpan di cool box untuk mencegah perubahan warna. Identifikasi spesies dilakukan di lâborratorium Hidrobioekologi Manajemen Sumberdaya Perairan (HBMSP) dengan menggunakan petunjuk identifikasi menurut Lanyon (1986) dan Menez et al. (1983).

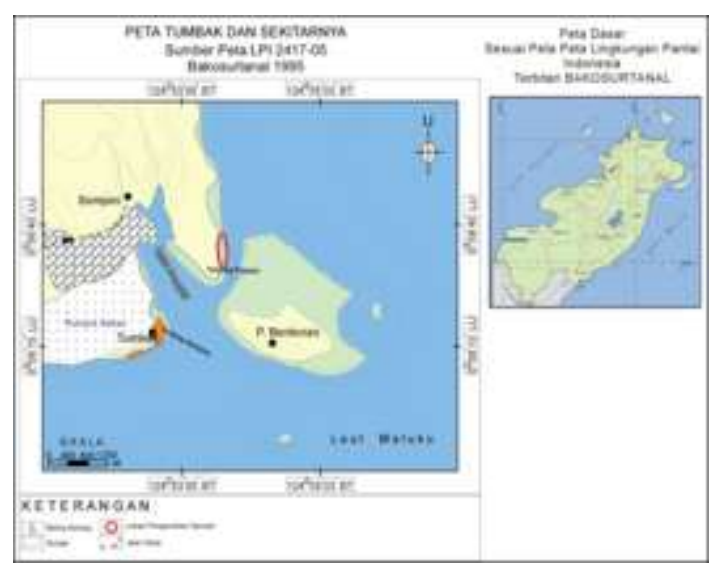

Gambar 1. Peta Lokasi Penelitian

\section{HASIL}

\section{Komposisis Spesies}

Ditemukan tujuh jenis rumput laut yang di identifikasi berdasarkan panduan Lanyon (1986) dan Menez et al, (1983) yaitu Cymodocea rotundata, 
C. serrulata, Halophila ovalis, H. minor, Syringodium isoetifolium, Thalassia hemprichii, dan Enhalus acoroides. Namun dari ketujuh Spesies tersebut yang masuk dalam kuadrat transek hanya ada empat jenis yaitu $C$. rotundata, $C$. serrulata, $H$. ovalis, dan $E$. acoroides.

\section{Biomassa dan Biomassa Relatif}

Hasil biomassa $\left(\mathrm{g} / \mathrm{m}^{2}\right)$ untuk lokasi transek 1 menunjukkan bahwa nilai biomassa tertinggi ditemukan pada spesies rumput laut $E$. acoroides sebesar $1273 \mathrm{~g} / \mathrm{m}^{2}$, diikuti oleh $C$. rotundata sebesar $815,5 \mathrm{~g} / \mathrm{m}^{2}, \quad C$. serrulata sebesar $319 \mathrm{~g} / \mathrm{m}^{2}$, dan $H$. ovalis $265 \mathrm{~g} / \mathrm{m}^{2}$. Untuk lokasi transek 2 , nilai biomassa tertinggi ditemukan pada C. rotundata sebesar $1512 \mathrm{~g} / \mathrm{m}^{2}$, diikuti E. acoroides sebesar $1105,5 \mathrm{~g} / \mathrm{m} 2, C$. serrulata sebesar $96 \mathrm{~g} / \mathrm{m}^{2}, H$. ovalis sebesar $76 \mathrm{~g} / \mathrm{m}^{2}$. Sedangkan untuk lokasi transek 3 nilai biomassa tertinggi pada $E$. acoroides sebesar $1139 \mathrm{~g} / \mathrm{m}^{2}$ diikuti oleh $C$. serrulata sebesar 198 $\mathrm{g} / \mathrm{m}^{2}$.

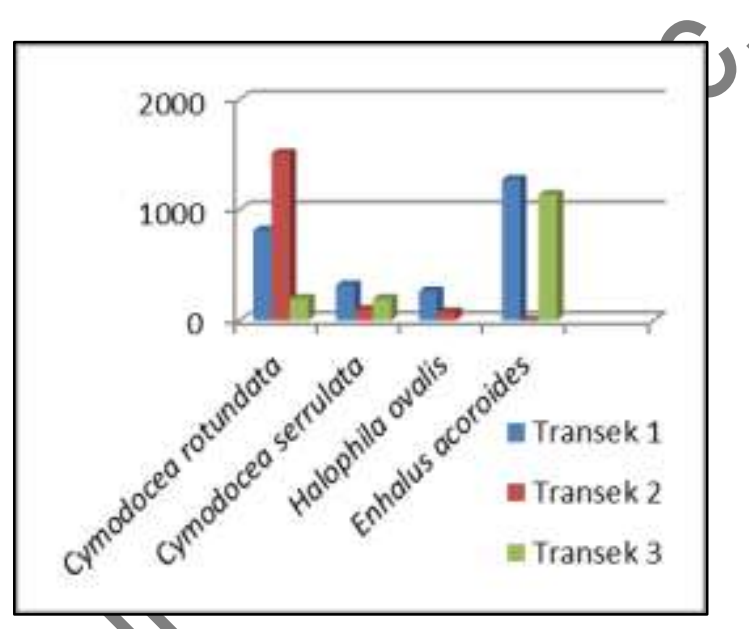

Gambar 2. Biomassa Rumput Laut

\section{Kepadatan dan Kepadatan Relatif}

Nilai kepadatan jenis (ind $/ \mathrm{m}^{2}$ ) tertinggi pada transek 1 diperoleh pada spesies $H$. ovalis $\left(132,5 \mathrm{ind} / \mathrm{m}^{2}\right)$ diikuti spesies C. rotundata $\left(116,5 \mathrm{ind} / \mathrm{m}^{2}\right)$. Untuk transek 2 kepadatan tertinggi pada $C$. rotundata $\left(216 \mathrm{ind} / \mathrm{m}^{2}\right)$ diikuti E.acoroides $(148,5 \mathrm{ind} / \mathrm{m} 2), H$. ovalis (34 ind $/ \mathrm{m}^{2}$ ) dan C.serrulata (16 ind $/ \mathrm{m} 2$ ).
Sedangkan pada transek 3 kepadatan tertinggi $C$. serrulata $\left(88 \mathrm{ind} / \mathrm{m}^{2}\right)$ diikuti E. acoroides (17 ind $\left./ \mathrm{m}^{2}\right)$.

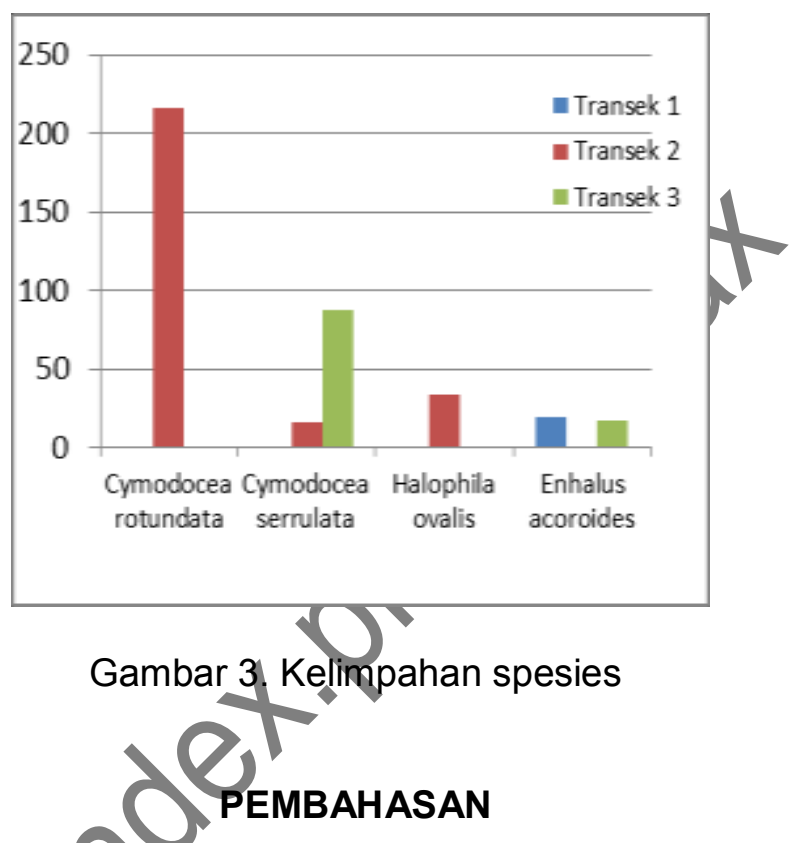

Parameter Lingkungan

- Hasil pengukuran suhu air laut di lokasi penelitian sebesar $29^{\circ} \mathrm{C}$ menunjukkan bahwa kondisi itu sangat cocok dengan pertumbuhan rumput laut. Hal itu sesuai dengan pernyataan Zieman, (1975) in Kordi, (2011) yang menyatakan bahwa suhu optimum pertumbuhan rumput laut adalah sebesar $28-30^{\circ} \mathrm{C}$.

Hasil pengukuran salinitas di lokasi penelitian tercatat $31 \%$. Hasil ini masih dalam batas toleransi kondisi optimum salinitas perairan yang sangat cocok dengan pertumbuhan ekosistem rumput laut. Kondisi ini Secara umum merupakan salinitas yang optimum untuk pertumbuhan rumput laut yaitu berkisar 25-35\%o (Dahuri, 2003 in Kordi, 2011).

Substrat di lokasi penelitian sebagian besar didominasi pasir, lumpur dan pecahan karang mati. Kondisi substrat ini sangat cocok dengan pertumbuhan ekosistem rumput laut. Seperti yang dinyatakan oleh Hutomo et all, (1988) in Kordi, (2011) menyatakan bahwa ekosistem rumput laut akan tumbuh dengan baik di daerah yang terlindung, bersubstrat pasir, lumpur, pecahan karang 
mati, serta dekat sedimen yang bergerak secara horisontal.

\section{Biomassa dan Biomassa Relatif}

Secara keseluruhan biomassa dan biomassa relatif tertinggi diwakili oleh spesies $E$. acoroides diikuti oleh $C$. rotundata, $C$. serrulata dan $H$. ovalis.

\section{Struktur Komunitas}

Jumlah spesies yang ditemukan di lokasi penelitian terdapat tujuh spesies yaitu C. rotundata, C. serrulata, $E$. acoroides, $H$. ovalis, $H$. minor, $T$. hemprichii, $S$. isoetifolium.

Kiswara (1996) dalam penelitiannya di Teluk Gerupuk dan Kuta, Lombok Nusa Tenggara Barat menyatakan bahwa rumput laut spesies $E$. acoroides, $T$. hemprichii, $H$. ovalis, $H$. minor, $C$. rotundata, C. serrulata, S. isoetifolium umumnya ditemukan di daerah pasang surut hingga tepi tebing pantai pada substrat pasir, pasir halus, lumpur dan pecahan karang mati. Hal ini sesuai dengan kondisi lokasi penelitian di perairan Desa Tumbak. Selanjutnya Susetiono (2004) menyatakan bahwa komposisi spesies suatu rumput laut sangat berkaitan erat dengan kelimpahan dan keanekaragaman fauna yang berasosiasi di dalam komunitas rumput laut tersebut.

\section{Kepadatan dan Kepadatan Relatif}

Kepadatan spesies dan kedapatan relatif menunjukkan hasil yang berbeda tiap transek. Untưk transek 1 kepadatan spesies dan kepadatan relatif tertinggi di wakili oleh spesies $H$. ovalis dan $C$. rotundata, di transek 2 kepadatan spesies dan relatif tertinggi diwakili oleh C. rotundata dan $H$. ovalis, sedangkan dintransek 3 kepadatan spesies dan relatif tertinggi diwakili oleh $C$. serrulata dan E. acoroides. Perbedaan ini kemungkinan besar disebabkan oleh perbedaan kemampuan menyesuaikan diri terhadap kondisi lingkungan dimana organisme itu hidup. Cappenberg (2000) in Mokodompit (2006) menyatakan kepadatan suatu organisme ditentu-kan oleh kemampuan menyesuaikan diri dengan kondisi lingkungan dimana organisme tersebut hidup. Petersen (1991) in Takaendengan dan Azkab, (2010) menyatakan bahwa pengaruh dari pasang surut air laut yang berbeda tiap zona memungkinkan berkembangnya komunitas yang khas untuk masing masing zona di daerah itu.

\section{Keanekaragaman dan Kemerataan}

Hasil keanekaragaman spesies tertinggi terdapat pada transek 1 dan transek 2 dimungkinkan karena tipe substrat yang lebih bervariasi dibandingkan pada transek 3. Secara keseluruhan nilai keanekaragaman dan kemerataan spesies mendekat nilai satu yang menunjukkan bahwa penyebaran individu di setiap spesies lebih merata dan relatif stabil. Cappenberg (2002) in Mokodompit (2006) menjelaskan bahwa suatu komunitas dikatakan baik dan stabil apabila nilai kemerataan spesies mendekati 1.

\section{KESIMPULAN} Berdasarkan hasil penelitian
tentang struktur komunitas dan biomassa rumput laut (seagrass) di Perairan Desa Tumbak Kecamatan Pusomaen Kabupaten Minahasa Tenggara dapat disimpulkan sebagai berikut :

- Jenis rumput laut yang ditemukan di lokasi penelitan berjumlah tujuh spesies, empat spesies berada dalam kuadrat yaitu Cymodocea rotundata, Cymodocea serrulata, Halophila ovalis, dan Enhalus acoroides, dan ditemukan tiga spesies di luar kuadrat yaitu Halophila minor, Syringodium isoetifolium dan Thalassia hemprichii.

- Secara keseluruhan biomassa dan biomassa relatif tertinggi diwakili oleh spesies $E$. acoroides, C. rotundata, C. serrulata dan $H$. ovalis. Hal ini dikarenakan oleh perbedaan jumlah individu, ukuran spesies dan kepadatan spesies.

- Hasil keanekaragaman spesies tertinggi terdapat pada transek 1 dan 2 dimungkinkan karena tipe substrat 
yang lebih bervariasi dibandingkan pada transek 3. Hal ini diduga kondisi lingkungan ke dua transek (2 dan 1) lebih stabil dalam hal ketersediaan zat hara sehingga kompetisi antar spesies relatif dan tidak terjadi dominasi spesies.

\section{DAFTAR PUSTAKA}

Kordi, K.H.G.M. 2011. Ekosistem Lamun (seagrass) : fungsi, potensi, pengelolaan. Jakarta: Rineka Cipta, 191 hal.

Kiswara, W. 1996. Inventory of Seagrass in Kuta and Gerupuk Bays, Lombok Indonesia. Seagrass Biology: Procedings of an international workshop. p. 27-32.

Lanyon, J. 1986. Guide to the Identification of Seagrasses in the Great Barrier Reef Region. Great Barrier Reef Park Authority Special
Publication Serries (3) Townville, Queesland Australia. 54 p.

Menez, G.E, G.R. Phillips and P.H. Calumpong. 1983. Seagrasess from the philippines. Smithsonian Institution press. City of Washington. $40 \mathrm{p}$.

Mokodompit L. 2006. Komunitas Rumput Laut (seagrass) di Perairan Pantai Desa Boyong Pante Kecamatan Sinonsayang Kabupaten Minahasa Selatan. Skripsi FPIKUNSRAT. 57 hal.

Susetiono, 2004. Fauna Padang Lamun Tanjung Merah Selat Lembeh. Pusat Penelitian Oseanografi-LIPI. 106 hal.

Takaendengan, K dan M. H. Azkab. 2010. Struktur Komunitas Lamun Di Pulau Talise, Sulawesi Utara. Oseanologi dan Limnologi Di Indonesia (2010) 36 (1) :85-95 